\title{
Staged and primary Yasui repair in infants with interrupted aortic arch
}

\author{
Jacek Pająk', Maciej A Karolczak', Wojciech Mądry' ', Izabela Pągowska-Klimek², Jacek Kuźma' \\ 'Department of Cardiac and General Pediatric Surgery, Medical University of Warsaw, Warszawa, Poland \\ ${ }^{2}$ Department of Pediatric Anesthesiology and Intensive Therapy, Medical University of Warsaw, Warszawa, Poland
}

\author{
Correspondence to: \\ Jacek Kuźma, MD, \\ Department of Cardiac and \\ General Pediatric Surgery, \\ Medical University of Warsaw, \\ Żwirki i Wigury 63A, 02-091 \\ Warszawa, Poland, \\ phone: +48 223179881 , \\ e-mail: kuzmajacek@yahoo.com \\ Copyright by the Author(s), 2022 \\ DOI: 10.33963/KP.a2022.0003 \\ Received: \\ December 8, 2021 \\ Accepted: \\ January 3, 2022 \\ Early publication date: \\ January 4, 2022
}

The techniques and indications for the Yasui operation have evolved from the first procedure performed in 1987 in children with complex heart defects: severe left ventricular outflow tract obstruction (LVOTO), ventricular septal defect (VSD), interrupted aortic arch (IAA), and well developed two ventricles [1]. The operation can be performed as primary correction or staged repair in children with high early mortality risk reaching even 18\%$-23 \%$, especially in children with low body weight and coexisting organ defects [2-4]. The procedure includes the reconstruction of the IAA with Damus-Stansel-Kaye or Norwood techniques, implantation of the right ventricle (RV) - pulmonary artery (PA) prosthesis, and the closure of VSD rerouting the blood from the left ventricle (LV) to the pulmonary trunk [1-4].

We present cases of two newborns operated on with the staged as well as primary Yasui operation following Kanter's operative techniques [2].

Case 1: A 10-day-old female newborn with D-malposition of the great arteries, double outlet right ventricle (DORV, Taussig-Bing type) (Supplementary material, Video S1), subaortic stenosis, subpulmonary VSD (Supplementary material, Video S2), IAA (type A), and patent arterial duct (Supplementary material, Video S3), was operated on with the primary Yasui correction in cross-clamp circulation and deep hypothermia. The aortic arch was reconstructed with biological CorMatrix $\mathrm{Cor}^{\mathrm{TM}}$ PATCH (CorMatrix Cardiovascular Inc., GA, USA). RV-PA connection was provided by the $12 \mathrm{~mm}$ valved conduit Contegra with a bovine jugular vein (Medtronic Inc, MN, USA). VSD was closed with a patch. In the early postoperative follow-up, the patient required reoperation due to LV-right atrial shunt and finally was discharged home in a good condition.

Case 2: A 14-day-old female newborn with LVOTO (conal septum posterior malalignment), large VSD (Figure 1A, Supplementary material, Video S4), atrial septal defect (ASD), IAA (type $B$ ) with a retroesophageal right subclavian artery and patent arterial duct (Figure 1B) was operated on with staged repair due to low body weight and severe cardiac compromise.

The first stage included the aortic arch reconstruction with the patch from the left subclavian artery and CorMatrix PATCH with Norwood technique (Figure 1C, Supplementary material, Video S5) and Sano modification (5 mm PTFE RV-PA conduit) (Figure 1D, Supplementary material, Video S6) without VSD closure. Eight months later, the Yasui correction with the Rastelli-type procedure was performed with VSD closure (Figure 1E, F, Supplementary material, Video S7, and S8) and $14 \mathrm{~mm}$ pulmonary valved conduit Contegra implantation to establish RV-PA continuity. The postoperative follow-up was uncomplicated.

In an 18-month follow-up, the patients were in good condition (the New York Heart Association [NYHA], class I) awaiting the heart catheterization due to RV-PA distal Contegra stenosis.

In both cases, the Yasui operation provided a double-lumen LV outflow tract with aortic arch reconstruction and RV-PA continuity, which was an alternative option for biventricular repair.

A staged approach had a lower risk of reoperation and mortality, although in all children RV-PA prosthesis stenosis, as well as reconstructed aortic arch obstruction or even 

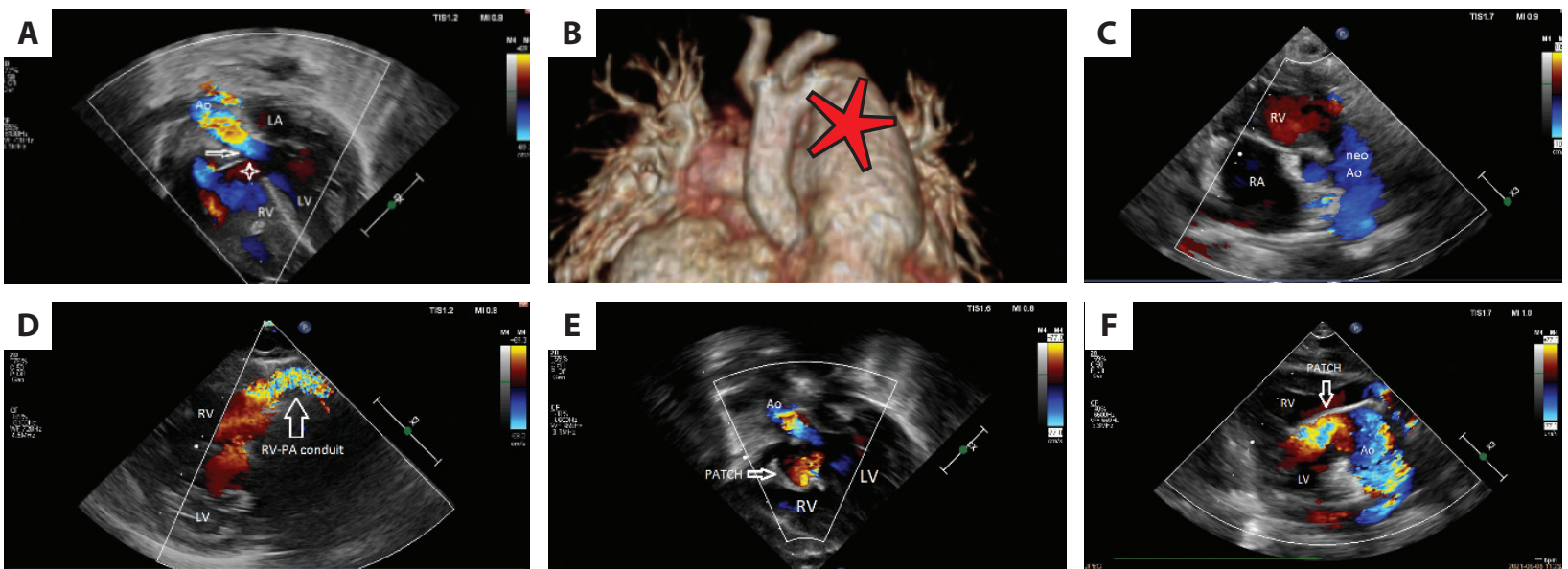

Figure 1. A. Transthoracic echocardiographic. 5-chamber view with well-developed two ventricles, large ventricular septal defect (star), and left ventricular outflow tract obstruction (arrow). B. 3D rendered computed tomography — interrupted aortic arch (type B) with large patent arterial duct (red star). C. Norwood procedure with aortic arch reconstruction. D. Sano modification with the right ventricle - pulmonary artery anastomosis. E, F. Large patch (white arrow) providing double-lumen left ventricular outlet tract

Abbreviations: Ao, aorta; LA, left atrium; LV, left ventricle; RA, right atrium; RV, right ventricle

dissection, may appear in follow-up with the necessity for surgery or complex endovascular interventions including balloon angioplasty or stent-graft implantations [5].

\section{Supplementary material}

Supplementary material is available at https://journals. viamedica.pl/kardiologia_polska.

\section{Article information}

Conflict of interest: None declared.

Open access: This article is available in open access under Creative Common Attribution-Non-Commercial-No Derivatives 4.0 International (CC BY-NC-ND 4.0) license, allowing to download articles and share them with others as long as they credit the authors and the publisher, but without permission to change them in any way or use them commercially. For commercial use, please contact the journal office at kardiologiapolska@ptkardio.pl.

\section{REFERENCES}

1. Yasui $\mathrm{H}$, Kado $\mathrm{H}$, Nakano $\mathrm{E}$, et al. Primary repair of interrupted aortic arch and severe aortic stenosis in neonates. J Thorac Cardiovasc Surg. 1987; 93(4): 539-545, doi: 10.1016/50022-5223(19)36381-0, indexed in Pubmed: 3561000 .

2. Kanter K. The Yasui operation. Oper Tech Thorac Cardiovasc Surg. 2010; 15(3): 206-222, doi: 10.1053/j.optechstcvs.2010.08.001.

3. Nakano T, Kado H, Tatewaki H, et al. The Yasui operation for patients with adequate-sized ventricles and ventricular septal defect associated with obstructions of the aortic arch and left ventricular outflow tract. Eur J Cardiothorac Surg. 2014; 45(5): e166-e172, doi: 10.1093/ejcts/ezt658, indexed in Pubmed: 24482388.

4. Suzuki T, Ohye R, Devaney E, et al. Selective management of the left ventricular outflow tract for repair of interrupted aortic arch with ventricular septal defect: Management of left ventricular outflow tract obstruction. J Thorac Cardiovasc Surg. 2006; 131(4): 779-784, doi: 10.1016/j. jtcvs.2005.11.038, indexed in Pubmed: 16580434.

5. Weryński P, Kołcz J, Król-Jawień W, et al. Multiple extremely high-risk endovascular interventions in aortic dissection in an infant with interrupted aortic arch. Kardiol Pol. 2020; 78(5): 472-473, doi: 10.33963/kp.15238, indexed in Pubmed: 32189487. 